\section{The Role of Resonant Leadership, Workplace Friendship and Serving Culture in predicting Organizational Commitment: the Mediating Role of Compassion at Work}

\author{
Riaz Ali ${ }^{1}$ \\ ${ }^{1}$ The Savvy School, Gujranwwala, Pakistan \\ Muhammad Kashif ${ }^{2,3}$ \\ ${ }^{2}$ GIFT University, Gujranwwala, Pakistan \\ ${ }^{3}$ Researcher, FGS, University of Colombo, Sri Lanka
}

Received on:

07/24/2019

Approved on:

04/16/2020

Responsible Editor:

Prof. Dr. Pattanee Susomrith

\section{Evaluation process:}

Double Blind Review

\begin{abstract}
Purpose - This study aims to empirically demonstrate the positive effects of resonant leadership, workplace friendship and serving culture on organizational commitment through a mediating role of compassion at work.

Design/methodology/approach - The data are collected from 442 front line employees (FLEs) working in Pakistani healthcare organizations by employing a cross-sectional survey. The collected data are analysed through the structural equation modelling (SEM) technique, using SmartPLS 3.0.
\end{abstract}

Findings - All the proposed relationships are statistically supported. We found that resonant leadership, serving culture and workplace friendship predict normative commitment among healthcare frontliners through a mediating role of compassion at work. The results demonstrate an excellent model fit, where all the direct as well as indirect hypotheses are supported by the data.

Originality/value - The analysis of the positive effects of resonant leadership, workplace friendship and serving culture as a unified framework to predict organizational commitment via the mediating role of compassion in a healthcare setting is unique to this study.

Keywords - Compassion at Work, Resonant Leadership, Workplace Friendship, Serving Culture, Organizational Commitment

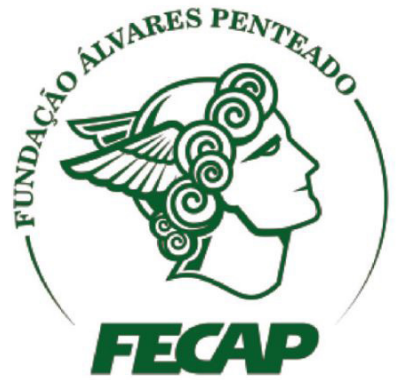

Revista Brasileira de Gestão de Negócios

https://doi.org/10.7819/rbgn.v22i4.4085 


\section{Introduction}

Organizational commitment is employees' attitude and loyalty towards their employer (Kumasey, Bawole, \& Hossain, 2017; Lee \& Reade, 2018). Committed employees serve customers in the best possible manner, which results in the establishment of stronger employeecustomer relationships (Ansari \& Kashif, 2019; Mawritz, Folger, \& Latham, 2014). The context of frontliners is important as they are expected to demonstrate socially desirable emotions during the service work they carry out, which is a challenging task as organizations have so far failed to provide an environment which positively triggers prosocial behaviours (van Gelderen, Konijn, \& Bakker, 2017). At the baseline, there is evidence that lower levels of employee commitment to the organization results in poor emotional displays during service performance (Kashif, Zarkada, \& Thurasamy, 2017a; Krannitz, Grandey, Liu, \& Almeida, 2015). However, when employees decide to remain committed to an organization, there is an ensured tendency to display positive behaviours at work (Schwepker, Dimitriou, \& McClure, 2019).

In order to strengthen employee commitment, Lilius and colleagues (Lilius, Worline, Dutton, Kanov, $\&$ Maitlis, 2011) proposed an environment based on compassion. Compassion has been discussed in the human relations literature over the years and involves elements of inner feelings towards others and sympathizing and relating with the pain of another person (Kanov et al., 2004). In organizational settings, compassion has been discussed as a feeling where someone is deeply concerned about avoiding other people's suffering, in order to ensure their well-being (Dutton, Worline, Frost, \& Lilius, 2006; Ge, Wu, Li, \& Zheng, 2019). Thus, compassion is an empathic response towards others and is different than other constructs such as voluntary behaviours. When displaying voluntary behaviours, individuals act to help others (i.e. working for others, talking and listening), while compassion comprises an emotion that leads to organization-centric behaviours and prevents them from engaging in uncivil behaviours at work (Rhee, Hur, \& Kim, 2017). Compassionate individuals not only feel others' pain but are also ready to render material support (Dutton et al., 2006). Compassion at work involves various stages: (a) noticing the pain of another person, (b) having an emotional reaction towards his/her pain, and (c) responding in a way to help and reduce or eradicate that pain (Kanov et al., 2004). These feelings are a product of a comfortable and inspiring workplace culture (Lilius et al., 2011). Such feelings (i.e. compassion) can lead to several positive outcomes, such as employee commitment. For instance, feelings of compassion have been found to trigger proactive and positive behaviours among employees (Hur, Moon, \& Ko, 2018; Rhee et al., 2017). In a similar argument, compassion can also lead to organizational commitment among employees, thus addressing a key issue facing service organizations (Kumasey et al., 2017).

In an era where employees working in service organizations feel depressed and face aggressive behaviours at work (Kashif et al., 2017a), the existence of compassion is important to minimize the dark effects of toxic environments (Rhee et al., 2017). In this regard, considering compassion as an outcome of positive organizational behaviours is pivotal. The organizational antecedents of compassion (i.e. the organizational factors that can trigger compassion at work) are unclear and are suggested as a potential area of inquiry (Madden, Duchon, Madden, \& Plowman, 2012). Since its inception in the early 2000s, organizational compassion has been examined extensively, but there is still a dearth of studies informing managers to impart compassionate feeling among employees at work (Shahzad \& Muller, 2016). There needs to be positive leadership, friendly workplace relationships, and a culture of support to trigger compassionate feelings among employees (Kanov et al., 2004). In line with these guidelines, we present resonant leadership, workplace friendship and serving culture as three new antecedents of compassion at work.

Relationship-oriented leadership styles trigger positive emotions among employees. In this regard, resonant leadership, a relationship-oriented leadership style, is found to trigger positivity among employees (Boyatzis \& McKee, 2013; Cummings et al., 2010). Resonant leaders establish stronger emotional bonds with their employees (Koman \& Wolff, 2008); they are positive, caring, and spread hope, which enables them to establish stronger emotional ties with their followers (Goleman, Boyatzis, \& McKee, 2013). Resonant leaders are able to establish a culture of support and positivity at work (Bawafaa, Wong, \& Laschinger, 2015), which can stimulate employees to display proactive behaviours (Schwepker et al., 2019). Resonant leadership behaviour results in positive work outcomes, but its association with compassion at work to drive commitment among employees remains unclear (Zulueta, 2016). There may be 
other leadership behaviours; however, resonant leadership behaviours are found to drive mindfulness and empathy among followers (Singh, Sengupta, \& Sharma, 2018). Resonant leadership involves a relationship-oriented approach to leading followers. The relationship between leadership and proactive behaviours has already been presented, but the importance of resonant leadership to trigger compassionate feelings at work is often missed (Hur et al., 2018). This is an important research gap that may inform managers to practice a certain type of leadership style in order to inculcate compassion among employees, which is regarded as pivotal in ensuring success (Hur et al., 2018).

Friendship at work is yet another important element to strengthen positive behaviours in the workplace. When working together, employees socialize with each other, which can lead to a caring attitude. But this has been missed in recently published studies (Methot, Lepine, Podsakoff, \& Christian, 2016). Friendship at work is an important element to counter workplace bullying and related aggressions, also helping individuals to counter work-related stress and depression (Rai \& Agarwal, 2018b). However, friendship at work is not very natural and requires some rationalization and strategies to inject this spirit among employees (Chang, Chou, Liou, $\& \mathrm{Tu}, 2016)$. When employees become friends, their friendship can counter bullying and aggression and also strengthens their commitment to the company (Chao, 2018). However, whether friendship at work results in employees showing compassion towards each other is an important research question that remains unaddressed by contemporary researchers (Rai \& Agarwal, 2018a). Since episodes of abuse at work are common (Kashif et al., 2017a), stronger emotional ties among colleagues have the potential to eliminate the negative effects of dark behaviours at work (Chiaburu \& Harrison, 2008). This is where we believe workplace friendship has the potential to trigger compassion at work.

Finally, a serving culture is yet another organizational element that can trigger compassion and ultimately organizational commitment. A serving culture is defined as a culture of support, care and trustworthiness, where all the members of an organization are engaged in serving behaviours (Liden, Wayne, Liao, \& Meuser, 2014). This is not limited to serving customers but also involves helping colleagues as well. Theoretically, a serving culture is categorized as an important facet of such work environments, where all the members prioritize and try to serve the needs and interests of others, supporting and helping each other (Nowak, 2019). When employees perceive organizational-related elements as positive being for their well-being and performance it results in positive work outcomes and has the potential to trigger commitment to the organization. However, even in the presence of such positive work environments, there is a noted lack of organizational commitment (Jang \& Kandampully, 2018). Therefore, the relationship between a positive perception of the work environment and commitment requires some intervention. With this important gap in mind, we present compassion as a result of a perceived serving culture to strengthen its relationship with organizational commitment among employees. Compassion at work is a feeling among employees that triggers positive performance and behaviours at work (Hur et al., 2018).

There are three types of commitment: affective, continuance, and normative commitment (Allen \& Meyer, 1990). Affective commitment is an emotional response to organizational efforts, while continuance commitment is where employees perform a cost-benefit analysis regarding whether to stay at or leave the company. Normative commitment is employees' perceptions of an "obligation to stay" with the organization (Meyer \& Allen, 1997). Normative commitment is a balanced judgement among employees to stay with the company and is a consequence of the arousal of some inner feelings among them. This happens when they feel that staying with the company is a moral duty and that the organization's mission is compelling, motivating them to care about and help its members (McCormick \& Donohue, 2019). Normative commitment among employees is a real challenge facing service organizations and managers are pressed to find ways to strengthen employee-organization relationships (Sharma, Kong, \& Kingshott, 2016). Despite being a rational and important attitude, normative commitment is often overlooked, while affective commitment has been studied extensively (McCormick \& Donohue, 2019). For instance, affective organizational commitment has been studied as a consequence of resonant leadership behaviour (Laschinger, Wong, Cummings, \& Grau, 2014), workplace friendship (Morrison, 2009) and a serving culture (Liden et al., 2014), but these important organizational variables are rarely positioned to investigate their impact on normative organizational commitment. Contemporary researchers have recommended investigating normative commitment to further present its organizational antecedents, which can advance the knowledge in the field of organizational 
behaviour (McCormick \& Donohue, 2019). Our study has the potential to offer valuable guidelines for organizations seeking to strengthen employees' normative commitment and those pursuing the development of compassion during service work. This is important since there is a lack of employee commitment in organizations (Jang \& Kandampully, 2018; McCormick \& Donohue, 2019) and compelling reasons for compassion during service work (Hur et al., 2018; Rhee et al., 2017).

\section{Concept and Hypotheses Development}

The framework is based on Social Learning Theory (SLT). This theory assumes that people learn from each other through social interactions and that their environment has an impact on them (Bandura, 1977, 1986). Similarly, when there is positivity at work, the experience of positive interactions can trigger positive behaviours among employees (Chiaburu \& Harrison, 2008). Employees in organizations learn to respect each other through observing the behaviour of peers and supervisors (Chen, Zhu, \& Zhou, 2015). This is how they learn to prioritize each other's needs (Liden et al., 2014), enabling members to collectively notice, feel and actively respond to induce positive behaviours at work (Wagner, Warren, Cummings, Smith, \& Olson, 2013), and compassion is no exception. In line with these assumptions, we consider three organizational antecedents as elements that are experienced by employees when they learn compassion, resulting in normative commitment. Compassion as a consequence of environmental factors has been studied recently using SLT, which strengthens our choice of the theory to explain the proposed relationships (ZoghbiManrique-de-Lara \& Viera-Armas, 2019).

\section{I Resonant leadership and compassion at work}

Resonant leadership is a leadership style where leaders are mindful, optimistic, and show empathy by focusing on the social and emotional needs of their followers, resulting in positive work outcomes (Boyatzis $\&$ McKee, 2013). Resonant leaders support and empower their followers, which can trigger positivity among them (Cummings, 2004), resulting in the achievement of personal as well as organizational goals (Marques, 2010). As positive leadership styles trigger compassion at work (Zulueta, 2016), the relationship between resonant leadership and compassion is important, yet it is rarely proposed. Employees observe leadership styles and act accordingly. As resonant leaders have high emotional competencies, they are able to develop empathy among their followers (Goleman et al., 2013). Moreover, due to their ability to socialize and handle difficult situations at work with ease, resonant leaders are able to build strong social bonds with people at work, which can result in feelings of compassion in the workplace (Laschinger et al., 2014). Followers learn and respond accordingly, which is in accordance with the assumptions of Social Learning Theory. The relationship between resonant leadership and compassion at work was pointed out by researchers years ago (Boyatzis \& McKee, 2013) but still lacks an empirical examination. The resonant leadership style is important and needed in healthcare settings to trigger positivity among employees at work (Laschinger et al., 2014). Resonant leaders are able to impart confidence and can strengthen social bonds among their followers, which provides them with the strength to meet the tough emotional requirements to perform healthcare jobs (e.g. nursing) (Bawafaa et al., 2015). Compassion during healthcare service work is also important as employees cannot serve patients in an efficient manner unless they feel their pain and then respond accordingly, while offering some tangible support (Younas \& Maddigan, 2019). In the context of high pressure healthcare jobs, resonant leaders have this ability to emotionally heal their followers, which can easily lead to positive feelings, with compassion being no exception. Given the importance of the resonant leadership style and the need to trigger compassionate feelings among healthcare employees, we propose the following:

H1: A perceived resonant leadership positively arouses feelings of compassion among healthcare employees.

\subsection{Workplace friendship and compassion at work}

Friendship at work has the potential to enhance job involvement and excitement about the work among employees (Song \& Olshfski, 2008). This is because a strong emotional connection among peers at work has the potential to counter negative effects such as burnout, resulting from high pressure jobs (Chang et al., 2016). The positive outcomes of friendship at work are important for employees working in healthcare organizations, where jobs are stressful and employees are always required to 
demonstrate socially desirable behaviours in the workplace (Mawritz et al., 2014). Individuals who are close friends are more likely to exchange ideas in a trustful manner (Sias, 2005), which also reduces stress and anxiety, especially when the friends meet on a regular basis (both formally and informally), leading to positive work outcomes (Chan \& Mak, 2014). Workplace friendship helps to develop compassion at different stages. For instance, regular meetups enhance awareness and understanding (i.e. noticing, as a first step of compassion) (Lilius, et al., 2011), enabling people to work as a collaborative and unified unit to deliver value during service encounters (Kashif et al., 2017a). When employees experience trust, they learn it from each other, mainly through social interactions, which may lead to proactive behaviours (Dutton, Roberts, \& Bednar, 2010). This is consistent with the assumptions of Social Learning Theory. It is also possible in situations where individuals perceive that others care about them (Zulueta, 2016), driving knowledge sharing and team work in a trustful manner (Sias, 2005). Workplace friendship among colleagues working in healthcare organizations is important and has been found to contribute to positive outcomes (Coetzee, Ferreira, \& Potgieter, 2019). Hence, workplace friendship in healthcare organizations is a critical factor of success and can also lead to some other positive attitudes at work. We thus hypothesize the following: H2: Perceived workplace friendship positively arouses feelings of compassion among healthcare employees.

\subsection{Serving culture and compassion at work}

A culture of care and trust triggers positivity at work (Simpson, Clegg, \& Pina e Cunha, 2013). Researchers looking into compassion have stressed the need to establish a workplace culture of care to ensure a compassionate workplace climate (Lilius, Kanov, Dutton, Worline, \& Maitlis, 2011). The existence of such a climate motivates people to share their ideas and even their worries among each other. Such a positive culture is regarded as a prerequisite for compassion at work, but it has so far been barely examined (Dutton, Workman, \& Hardin, 2014). Our argument is more specifically based on a serving culture, which is a system of legitimate propagation and practices of shared beliefs and norms and has the potential to produce positive work outcomes (Liden et al., 2014). An organizational system works in a trickle-down manner, whereby the individuals behave in the way they are treated by the authorities; fair treatment leads to perceptions of fairness while abuse invites abusive behaviours (Mawritz, Mayer, Hoobler, Wayne, \& Marinova, 2012). This is exactly the core assumption of Social Learning Theory (Bandura \& Walters, 1977), whereby it is believed that people notice and learn through the behaviours of others, resulting in the production of similar behaviours. This learning and replication of behaviour among employees may result in a culture where people care about each other, notice each other's needs, including suffering, show empathy, and help each other in times of need, thus ensuring compassion (Dutton et al., 2014). A serving culture is of paramount importance for healthcare organization systems. There is evidence that a serving culture triggers a care-oriented philosophy, i.e. serving the needs of others first (Nowak, 2019), which has the potential to establish feelings of compassion among healthcare employees. Caring for others is important for healthcare organizations since this is the core responsibility of the employees in such a system (Younas \& Maddigan, 2019). Thus, we propose the following hypothesis:

$\mathrm{H} 3$ : A perceived serving culture positively arouses feelings of compassion among healthcare employees.

\subsection{Compassion at work and organizational normative commitment}

Organizational commitment refers to "the relative strength of an individual's identification with and involvement in a particular organization" (Porter \& Smith, 1970, as cited in Mowday, Steers, \& Porter, 1978, p. 4). There are three types: affective, normative and continuance. Normative organizational commitment results in highly positive work outcomes, such as employees' inrole and extra-role performance, and negatively correlates with employee turnover (Gatling, Kang, \& Kim, 2016). Normative commitment is an obligatory phenomenon at work and is translated as an "obligation to stay" with the organization (Meyer \& Allen, 1997). However, it is a challenge for it to occur because an organization needs some compelling reasons that can trigger a sense of obligation among its employees (McCormick \& Donohue, 2019). Since organizations are unable to find the means and ways to trigger this obligatory attitude, it is worthwhile investigating normative commitment further (Sharma et al., 2016). Theoretically, normative commitment is overlooked by researchers examining commitment, despite being 
highly important for service organizations (McCormick \& Donohue, 2019), particularly in healthcare (Tekingündüz, Top, Tengilimoğlu, \& Karabulut, 2017). Compassionate experiences at work drive affective organizational commitment (Lilius et al., 2008), a belief we extend to establish a relationship between compassion and normative organizational commitment. This is because feelings of compassion have the potential to result in several positive work outcomes for compassion providers, receivers, and also for the organization facilitating compassion processes (Dutton et al., 2014). This can result in employees taking pride in caring for and helping others voluntarily (Grant, Dutton, \& Rosso, 2008) and having the feeling of being recognized as leaders (Melwani, Mueller, \& Overbeck, 2012), which they learn while observing others in an organizational system. This argument is therefore based on Social Learning Theory: people learn and then practice positive and/or negative behaviours, determining the levels of compassion and normative commitment. Thus, we hypothesize the following:

H4: Experience of compassion at work positively relates to organizational normative commitment.

\subsection{The mediating role of compassion at work}

It is empirically demonstrated that leadership practices, culture, and employee relations can lead to positive work outcomes, but employees working in service organizations can still lack commitment (Glazer \& Kruse, 2008; Schwepker et al., 2019). This means that a positive work environment is not the proximal determinant of organizational commitment and there are other variables that intervene in this relationship (Bernerth, Walker, \& Harris, 2016). Organizational commitment is a consequence of resonant leadership behaviour because resonant leaders are able to arouse positive feelings among employees, which motivates them to remain committed to their organization (Laschinger et al., 2014; Wagner, Warren, Cummings, Smith, \& Olson, 2014; Wagner et al., 2013). However, organizational commitment takes time to develop and is a consequence of positive emotions among employees towards an organization, an issue that is barely examined in studies of leader behaviours and commitment (Borhani, Jalali, Abbaszadeh, \& Haghdoost, 2014). Compassion as a feeling of care and tangible help can intervene in this relationship. Peers propagate the actions of their colleagues, which can result in the development of caring emotions towards organizations. However, in these studies the discussion of compassion is limited and requires attention to form a bridge between serving culture and organizational commitment (Liden et al., 2014). Finally, friendship at work is yet another organizational-level factor that might ensure a compassionate experience at work (Song \& Olshfski, 2008). The relationship between organizational elements and normative commitment is not new but the link between organizational elements to commitment via compassionate behaviours among employees is missing in recent studies (McCormick \& Donohue, 2016, 2019).

Studying compassion to influence organizational elements and commitment is important for service firms where jobs are challenging, anxiety is the norm, and employees often switch organizations (Spanuth \& Wald, 2017). Even when leadership behaviours are positive and employees have friendly relationships with each other, job burnout among employees is still common (Chang et al., 2016), which impedes commitment at work. Low commitment levels hinder positive displays of socially desirable emotions at work (Kashif et al., 2017a; Krannitz et al., 2015). Furthermore, researchers have stressed that some caring emotions (e.g. compassion) strengthen the link between positive work behaviours and organizational commitment (Lee \& Reade, 2018; Reader, Mearns, Lopes, \& Kuha, 2017). Logically, organizational-level factors cannot trigger an obligatory attitude (i.e. normative commitment) unless a feeling of care and helping others (i.e. compassion) is aroused among individuals (Hur et al., 2018). Thus, we hypothesize the following:

H5: The relationship between perceived resonant leadership and organizational normative commitment is mediated through compassion at work.

H6: The relationship between perceived workplace friendship and organizational normative commitment is mediated through compassion at work.

H7: The relationship between a perceived serving culture and organizational normative commitment is mediated through compassion at work.

\section{Research Methods}

\section{I Sample and data collection procedures}

The research design is based on a cross-sectional time horizon, which is widely adopted in survey-based studies and is regarded as an economical and efficient way 
to collect data (Bryman, 2015). The sample population included frontliners working with healthcare service organizations. We approached nurses and frontline staff involved in patient reception and care, working in private hospitals located in the city of Lahore. Since they are extremely busy handling patients, we opted for a convenient sampling technique to collect the data. This is a technique recommended for researchers in circumstances where data collection is challenging (Saunders, 2011). The busy schedule of nurses and frontline support staff justifies the sampling approach. The target respondents for this study included hospital employees because compassion is important in their jobs, as they have to demonstrate socially desirable emotions to patients and their families (Zulueta, 2016).

The principle researcher visited various private sector hospitals in Lahore to collect the data. Formal ethical approvals were also sought from the hospital administration. After highlighting the importance of the study, which was explained by the researcher involved in the data collection, the approvals to collect the data were granted. This led to the distribution of 600 questionnaires to nurses and frontline staff engaged in patient care and reception. As a courtesy and also to ensure a reasonable response rate, snacks were offered to all the respondents.

In order to further strengthen the criteriological validity of this study, the respondents were qualified based on five years of work experience as frontliners with any hospital. This was to ensure that the respondents were well versed in hospitality sector issues facing frontline employees. In total, 442 fully completed questionnaires were received back, with a healthy response rate of 73.6 percent. We completed the data collection from hospitals located in Lahore in a five-month period. The subject-toitem ratio of 10:1, as recommended by researchers (Randall \& Gibson, 2013), was used to decide on the sample size (e.g., there must be 320 if there are 32 survey items).

Table 1 below shows the respondent demographics: Almost 13 percent of the respondents have advanced education (e.g., FCPS and others), 50 percent have earned a graduate/bachelor's degree (e.g. MBBS, BBA and BS IT), 27 percent have associate degrees (e.g. nursing courses) and 10 percent are high school graduates. The data were collected from admin (30 percent) and medical units (70 percent). In the Pakistani context, the vast majority of nurses are young females. Hence, the predominance of young female respondents is a reflection of the Pakistani healthcare context. (The research questionnaire employed in this study to collect data is shown in the appendix A)

\subsection{Measurements}

The variables of this study are measured through self-reported items on a 5-point Likert scale. The choice of measures adopted in the study is based on the strong alpha values, as reported in previous studies. Moreover, in order to measure these items, we used a Likert-scale ranging from $1=$ strongly disagree to $5=$ strongly agree for all constructs except compassion at work, which is measured as $1=$ never to $5=$ nearly all the time.

Table 1.

\section{Demographics of Respondents}

\begin{tabular}{cccc}
\hline Variables & & Frequency & Percentage (\%) \\
\hline Gender & Female & 323 & 73.1 \\
\hline Total & Male & 119 & 26.9 \\
\hline Age & 21 to 30 & 442 & 100 \\
\hline & 31 to 40 & 275 & 62.2 \\
\hline 41 to 50 & 89 & 20.1 \\
\hline Total & More than 50 & 15.8 & 1.80 \\
\hline Job Tenure & Less than One Year & 100 \\
\hline & 1 to 5 Years & 08 & 26.7 \\
\hline 6 to 10 Years & 442 & 45.9 \\
\hline Total & More than 10 Years & 203 & 12.0 \\
\hline
\end{tabular}




\subsection{Resonant leadership}

The resonant leadership style of the current supervisor was measured using a 10-item Resonant Leadership Scale $(\alpha=0.95)$ (Estabrooks, Squires, Cummings, Birdsell, \& Norton, 2009; Estabrooks, Squires, Hayduk, Cummings, \& Norton, 2011). It is sub-scale of the Alberta Context Tool (Estabrooks et al., 2011) and is employed extensively (Wagner et al., 2014). Items such as "My leader seeks feedback even if it is difficult to hear" and "My leader allows me the freedom to make important decisions in my work" were measured.

\subsubsection{Workplace friendship}

Workplace friendship is measured by adopting a 6 -item scale $(\alpha=0.85)$ employed by Nielsen, Jex, and Adams (2000). The original scale measures friendship opportunity and friendship prevalence, with 6 items each, while we used only 6 items for friendship prevalence to measure the strength and quality of relationship. This was decided by keeping in view the necessary condition to foster compassion at work. Items such as "I have formed strong relationships at work" and "I feel that someone I work with is a true friend" were measured.

\subsubsection{Serving culture}

Serving culture is measured through a 7 -item scale $(\alpha=0.82)$ developed and used by Liden and colleagues (Liden et al., 2014). The sample items included "Employee career development is a priority in my organization" and "Employees in my organization put others' best interests ahead of their own."

\subsubsection{Compassion at work}

Compassion at work is measured by a 3-item scale $(\alpha=0.79)$ developed and used by Lilius and colleagues (Lilius et al., 2008). The respondents were asked to rate the compassion they experienced while working with colleagues and supervisors. The items that measured the respondents' personal experiences of compassion included "How often do you experience compassion from your supervisor?" and "How often do you experience compassion from your co-workers?"

\subsubsection{Organizational normative commitment}

Finally, organizational normative commitment ( $\alpha=0.83$ ) (Meyer, Allen, $\&$ Smith, 1993) is measured by using a 6 -item scale. Items such as "The organization deserves my loyalty," and "I would feel guilty if I left my organization now" were measured.

\section{Data Analysis and Results}

We used the structural equation modelling (SEM) technique to analyse the collected data. Although regression analysis serves the purpose of predictive modelling, SEM is used by contemporary researchers due to its strengths in explicitly measuring relationships among latent variables (Lim, Kim, \& Shin, 2019). Initially, Harman's single factor test is used to address common method biases, and then we present the measurement model, structural model, and hypotheses tests.

\section{I Common method biases}

The data are self-reported, which requires the measurement of common method biases, as suggested by the experts (Podsakoff, MacKenzie, \& Podsakoff, 2012). Here, Harman's single factor test (Schriesheim, 1979) is used to statistically address the common method variance issues. This test has been widely accepted and used to assess common method biases by contemporary healthcare researchers when conducting studies in nursing and healthcare (Huyghebaert, Gillet, Audusseau, \& Fouquereau, 2019; Nguyen, Teo, Pick, \& Jemai, 2018), despite the criticisms (Min, Park, \& Kim, 2016). We used exploratory factor analysis (Podsakoff, MacKenzie, Lee, \& Podsakoff, 2003). The common latent factor should be less than 50 percent of the variance. Our analysis shows that it was 28.26 percent, which means that common method bias is not a problem in this study.

\subsection{Measurement model}

It has been empirically demonstrated that a value greater than 0.7 should be used to assess data for indicator loadings (Hair, Hult, Ringle, \& Sarstedt, 2016). In light of that, the analysis revealed that a few loadings have a value of less than 0.7 (i.e. RL1, WF1, SC5, SC6 and NC6). However, these indicators are not dropped because items with an outer loading higher than 0.60 are 
also accepted in previously conducted studies (Kashif, Zarkada, \& Thurasamy, 2017b).

Next, we measured for internal consistency. Composite reliability (CR) as a measure for internal consistency should show a value ranging from 0.7 to 0.9 (Hair et al., 2016). The CR values shown in Table 2 are within the range recommended by the experts. This ensures internal consistency for all the constructs. Construct validity is achieved by estimating the convergent validity (CV) and discriminant validity (DV). Convergent validity can be assured through the average variance extracted (AVE), which is a collective value that represents the central tendency of all the indicators' squared loadings and convergence towards a single construct (Neuman $\&$ Robson, 2012). The value must be equal to or greater than 0.5 (Hair et al., 2016). The analysis demonstrates that this value ranged between 0.50 and 0.62 , which confirms convergent validity for all the constructs, as presented in Table 2 below:
Discriminant validity is usually measured once convergent validity is confirmed (Hair et al., 2016). There are two methods used to assess discriminant validity, i.e. the cross loadings of each item and the Fornell-Larcker criterion, based on the square roots of the AVE values of each construct. We used the Fornell-Larcker criterion to assess the discriminant validity. The square roots of the AVE value of each construct must be larger than its maximum correlation with the other latent constructs (Hair et al., 2016). As shown in Table 3 below, discriminant validity (DV) is confirmed where the AVE values of each construct are higher than its correlations with other the constructs.

\section{$4 \cdot 3$ Structural model}

After establishing the reliability and validity of the measurement model, we evaluated the structural model, as recommended by the experts (Hair et al., 2016). The structural model can be assessed by following several steps. In order to determine that there is no

Table 2.

Internal Consistency, Reliability and Convergent Validity

\begin{tabular}{|c|c|c|c|c|c|}
\hline Constructs & Alpha & $\mathrm{CR}$ & Items & Loading & AVE \\
\hline \multirow[t]{6}{*}{ Resonant Leadership (RL) } & 0.80 & 0.86 & RL1 & 0.68 & 0.50 \\
\hline & & & RL4 & 0.71 & \\
\hline & & & RL5 & 0.72 & \\
\hline & & & RL6 & 0.72 & \\
\hline & & & RL7 & 0.70 & \\
\hline & & & RL8 & 0.73 & \\
\hline \multirow[t]{5}{*}{ Workplace Friendship (WF) } & 0.80 & 0.86 & WF1 & 0.64 & 0.56 \\
\hline & & & WF3 & 0.78 & \\
\hline & & & WF4 & 0.76 & \\
\hline & & & WF5 & 0.81 & \\
\hline & & & WF6 & 0.74 & \\
\hline \multirow[t]{6}{*}{ Serving Culture (SC) } & 0.80 & 0.86 & SC1 & 0.74 & 0.50 \\
\hline & & & SC2 & 0.71 & \\
\hline & & & SC4 & 0.72 & \\
\hline & & & SC5 & 0.69 & \\
\hline & & & SC6 & 0.69 & \\
\hline & & & SC7 & 0.71 & \\
\hline \multirow[t]{3}{*}{ Compassion at Work (CAW) } & 0.70 & 0.83 & CAW1 & 0.73 & 0.62 \\
\hline & & & CAW2 & 0.82 & \\
\hline & & & CAW3 & 0.81 & \\
\hline \multirow[t]{5}{*}{ Normative Commitment (NC) } & 0.82 & 0.87 & NC1 & 0.71 & 0.53 \\
\hline & & & $\mathrm{NC} 2$ & 0.78 & \\
\hline & & & NC3 & 0.72 & \\
\hline & & & NC4 & 0.74 & \\
\hline & & & NC5 & 0.75 & \\
\hline
\end{tabular}


collinearity among the constructs, the tolerance value must be higher than 0.20 and the VIF must be less than 5 to avoid empirical bias (Hair, Sarstedt, Hopkins, \& G. Kuppelwieser, 2014). The results revealed that our data are free from any collinearity issue as the values of the VIF test ranged from 1.157 to 1.833 (>0.20 and $<5)$ for all the constructs.

\subsection{Hypotheses testing}

\subsection{Direct and indirect effects}

We employed the bootstrapping technique to assess the relationships (direct and mediating) among the constructs, using 5000 subsamples. This technique is perfectly suited to the PLS-SEM method (Hair et al., 2016).

The beta value, standard error, $t$-statistics and $\mathrm{p}$-values are used to assess the significance of the direct effects of the exogenous constructs on the endogenous constructs. According to Hair, Ringle, and Sarstedt (2011), the critical t-values for a two-tailed test are: 1.65 (significance level $=10$ percent), 1.96 (significance level $=5$ percent ), and 2.58 (significance level $=1$ percent $)$.
All the proposed hypotheses of direct paths are accepted based on the $t$-values ( $t>2.58$, critical value) at the 1 percent significance level, as presented in Table 4 below. This means that resonant leadership positively relates to compassion at work $(\beta=0.20, t=3.84, \mathrm{p}<0.01)$, thus supporting $\mathrm{H} 1$. The second hypothesis is also supported, which implies that workplace friendship positively relates to compassion at work $(\beta=0.30, t=7.27$, $\mathrm{p}<0.01)$. Similarly, a serving culture positively relates to compassion at work $(\beta=0.23, \mathrm{t}=4.47, \mathrm{p}<0.01)$, thus supporting $\mathrm{H} 3$. Finally, compassion at work positively relates to normative commitment $(\beta=0.27, \mathrm{t}=5.84$, $\mathrm{p}<0.01$ ), supporting $\mathrm{H} 4$. These results are presented in Table 4 below:

Table 4 highlights that the relationship between resonant leadership and normative commitment is mediated by compassion at work $(\beta=0.05, \mathrm{t}=3.31$, $\mathrm{p}<0.01$ ), which supports H5. Similarly, the relationship between workplace friendship and normative commitment is mediated by compassion at work $(\beta=0.08, \mathrm{t}=4.55$, $\mathrm{p}<0.01$ ), thus supporting H6. Finally, the relationship between a serving culture and normative commitment

Table 3.

Discriminant Validity (Fornell-Larcker Criterion)

\begin{tabular}{cccccc}
\hline Constructs & CAW & NC & RL & SC & \\
\hline CAW & $\mathbf{0 . 7 9}$ & & & & \\
NC & 0.51 & $\mathbf{0 . 7 3}$ & $\mathbf{0 . 7 1}$ & $\mathbf{0 . 7 1}$ & \\
RL & 0.43 & 0.40 & 0.62 & 0.39 & $\mathbf{0 . 7 5}$ \\
SC & 0.47 & 0.46 & 0.28 & & \\
WF & 0.45 & 0.47 & &
\end{tabular}

Table 4.

\section{Path Coefficients}

\begin{tabular}{|c|c|c|c|c|c|c|}
\hline Hypotheses & Relationships & $\beta$ & SD & t-values & p-values & Decision \\
\hline \multicolumn{7}{|l|}{ Direct Effects } \\
\hline H 1 & $\mathrm{RL} \longrightarrow \mathrm{CAW}$ & 0.20 & 0.05 & 3.84 & $0.00^{* *}$ & Supported \\
\hline $\mathrm{H} 2$ & $\mathrm{WF} \longrightarrow \mathrm{CAW}$ & 0.30 & 0.04 & 7.27 & $0.00^{* *}$ & Supported \\
\hline $\mathrm{H} 3$ & $\mathrm{SC} \longrightarrow \mathrm{CAW}$ & 0.23 & 0.05 & 4.47 & $0.00^{* *}$ & Supported \\
\hline $\mathrm{H} 4$ & $\mathrm{CAW} \longrightarrow \mathrm{NC}$ & 0.27 & 0.05 & 5.84 & $0.00^{* *}$ & Supported \\
\hline \multicolumn{7}{|l|}{ Indirect Effects } \\
\hline $\mathrm{H} 5$ & $\mathrm{RL} \rightarrow \mathrm{CAW} \rightarrow \mathrm{NC}$ & 0.05 & 0.02 & 3.31 & $0.00^{* *}$ & Supported \\
\hline H6 & $\mathrm{WF} \rightarrow \mathrm{CAW} \rightarrow \mathrm{NC}$ & 0.08 & 0.02 & 4.55 & $0.00^{* *}$ & Supported \\
\hline $\mathrm{H} 7$ & $\mathrm{SC} \rightarrow \mathrm{CAW} \rightarrow \mathrm{NC}$ & 0.06 & 0.02 & 3.31 & $0.00^{* *}$ & Supported \\
\hline
\end{tabular}

Note. ${ }^{\star *}$ Significance at $1 \%$ 
is mediated by compassion at work $(\beta=0.06, \mathrm{t}=3.31$, $\mathrm{p}<0.01$ ), which supports $\mathrm{H} 7$.

\subsection{Model fitness}

A major part of structural model evaluations involves assessing coefficients of determination $\left(\mathrm{R}^{2}\right)$. The threshold values of $0.25,0.5$ and 0.7 are often used to describe a weak, moderate and strong coefficient of determination (Hair et al., 2016). Figure 1 demonstrates that three constructs, resonant leadership, workplace friendship and serving culture, collectively explain 33.10\% of the variance of the endogenous construct compassion at work. The overall $\mathrm{R}^{2}$ value is 0.331 . Similarly, resonant leadership, workplace friendship and serving culture along with compassion at work are found to jointly explain $37.4 \%$ of the variance of the endogenous construct normative commitment. The overall $\mathrm{R}^{2}$ value is 0.374 . These values represent the overall fitness of the model. The overall model fitness is assessed and presented in Figure 1 below:

The size of the effect $\left(f^{2}\right)$ of each independent variable on the $R^{2}$ value of its dependent variable is also calculated. The effect size is usually presented as small, medium or large, based on the threshold values of 0.02 , 0.15 , and 0.35 respectively (Hair et al., 2016). Finally, Stone-Geisser's $Q^{2}$ value is assessed to ensure the predictive relevance of the structural model, designed to evaluate the data points of items in a reflective measurement model (Hair et al., 2016). The threshold for predictive relevance should be $\mathrm{Q}^{2}>0$. $\mathrm{Q}^{2}$ values equal to $0.02,0.15$, and 0.35 predict weak, moderate and stronger degrees of predictive relevance of each effect. The $\mathrm{Q}^{2}$ values for compassion at work and normative commitment are 0.19 and 0.18 , respectively. These values confirm the predictive relevance of our model.

\section{Discussion}

This study is unique in examining the role of resonant leadership, serving culture, and workplace friendship in collectively predicting organizational commitment through the mediating role of compassion at work. Compassion at work is important, yet its organizational predictors are barely examined in recently-published studies (Zulueta, 2016). There are a few studies that discuss leadership style as a predictor of compassion at work, but its effect combined with other organizational variables is missing from contemporary studies (Zoghbi-Manrique-de-Lara $\&$ Viera-Armas, 2019). Affective commitment is studied extensively (Jang \& Kandampully, 2018), while normative commitment is relatively ignored (McCormick \& Donohue, 2019). This is especially true in the case of the healthcare service context, where an obligation to stay can result in proactive behaviours among employees (Zulueta, 2016). In an era where service managers are seriously looking to channel organizational commitment (Sharma et al., 2016), this study has pragmatic value for healthcare service providers.

All the direct as well as indirect relationships are statistically supported by the data, which has theoretical and practical implications. The relationship between resonant leadership and compassion at work is supported by the data, which can be explained by the fact that resonant leaders always notice the pain of their followers and respond accordingly (Spandler \& Stickley, 2011). Employees experience compassion at work in cases where the leaders demonstrate positive behaviours in the workplace (Koman \& Wolff, 2008). Resonant leaders are emotionally strong and take practical steps to address the worries of their followers, which can result in arousing feelings of compassion at work. The results are in line with those of previous studies where perceptions of ethical leadership result in compassion among employees (Zoghbi-Manrique-de-Lara \& Viera-Armas, 2019). This is how employees follow and learn from their supervisors or leaders.

The positive relationship between workplace friendship and compassion at work is statistically supported. This can be logically attributed to the role of friendly relationships at work, which form the basis for an instrumental and emotional support system for team members (Herman, Dasborough, \& Ashkanasy, 2008). Close friends socialize, learn from each other during social interactions and try to understand each other's worries, they feel empathy, and they love each other, which can easily lead to compassion at work. The results are in line with those of previous studies where friendship at work is found to contribute to positive work outcomes (Chao, 2018), considering compassion as a positive outcome of friendship.

The relationship between a serving culture and compassion is statistically supported and our study is the first to link these organizational elements with normative commitment via the arousal of compassion at work. In a working culture of care and support, people express their inner feelings openly (Frost et al., 2006). This facilitates noticing, feeling and responding to the suffering of 
others. This is how a serving culture fulfils the necessary condition to impart compassionate work experiences (Kanov et al., 2004). The culture has a trickle-down effect where justice leads to justice while aggression and abuse attract negative behaviours.

According to Mawritz et al. (2012), everything is learned and practiced accordingly. This is how we believe the relationship between a serving culture and compassion at work can be understood through Social Learning Theory (Bandura, 1977). The results are in line with those of previous studies where it is found that a serving culture helps organizations to establish a care-oriented work philosophy (Nowak, 2019). This is where we believe compassion, as a consequence of a serving culture, replicates the care-oriented philosophy in healthcare settings.

As a major finding of this study, the mediation of compassion is statistically supported. The mediation of compassion can be explained through Social Learning Theory (Bandura, 1977). Individuals learn from their leaders, friends, and sense care from the prevailing workplace culture, which can easily trigger feelings of compassion among them. The mediation results of our study are in line with recently published research where compassion at work is verified as a mediator that enriches and bridges the relationship between CSR and employee creativity (Hur et al., 2018). However, since the mediation of compassion is uniquely positioned between organizational elements and commitment, we explain it using logical arguments. Since leadership styles, workplace friendships and a serving culture are positively associated with positive work outcomes (Coetzee et al., 2019; Liden et al., 2014; Zoghbi-Manrique-de-Lara \& Viera-Armas, 2019), we replicate these positive outcomes with compassion at work. Considering compassion as a feeling among employees, there are studies where leadership styles (Hu et al., 2018) and stronger work relationships (Methot et al., 2016) are found to trigger positivity at work. Hence, our findings are in line with these previously-published studies and the relationship between organizational variables and commitment via compassion can be understood.

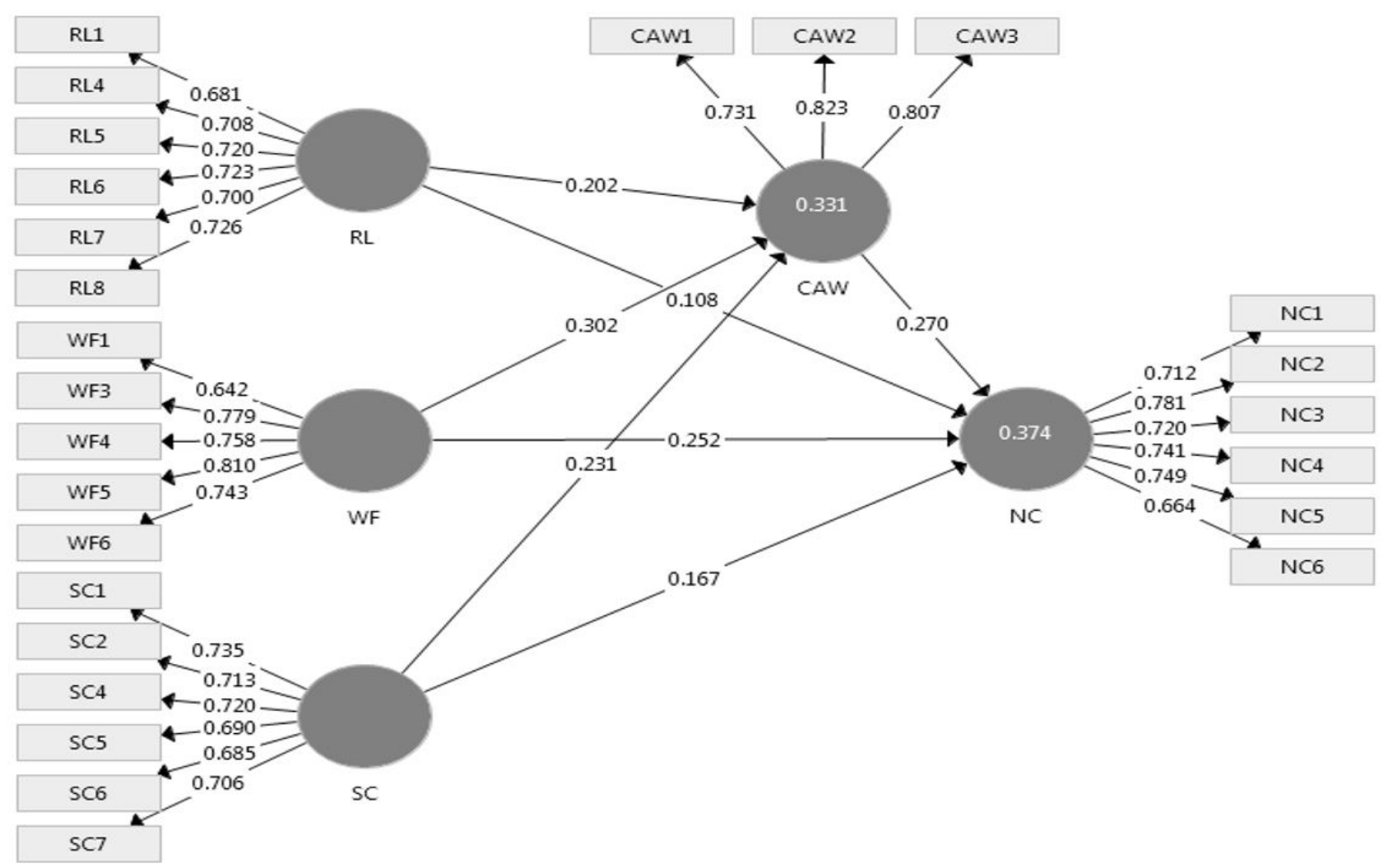

Figure 1. The Measurement Model 


\section{Managerial Implications}

The results reveal that resonant leadership, a serving culture and workplace friendship evoke compassionate feelings, resulting in normative commitment among healthcare employees. Based on these results, there are managerial implications which might be useful for service managers in healthcare organizations. First, healthcare service managers should strive for an environment where a mindful leadership style is used to manage employees. This is because resonant leaders are emotionally strong and can instil a similar spirit among their followers (Boyatzis \& McKee, 2013). This can help frontline staff to manage their emotions while performing service jobs in a high pressure healthcare setting. Second, managers need to ensure that their organization, or at least their unit, has a serving culture, which can trickle down and lead to positive attitudes at work (Mawritz et al., 2012). From a social learning perspective, when employees notice their peers and managers caring and helping others, this stimulates them to also demonstrate socially desirable behaviours, which is otherwise a challenging task (Zulueta, 2016). In a healthcare setting, when employees notice their peers caring for others (Laschinger et al., 2014) their in-role performance can be enhanced, thus making sure that a culture of care and love exists to drive compassion at work. Third, in order to ensure normative commitment, managers should work to arouse feelings of compassion among employees. They could seek help from the findings of this study to inculcate these feelings among frontliners. This can be done through a combination of leadership style, friendly relationships and also through the establishment of a culture of care and service.

\section{Limitations and Future Research}

The study has several limitations, which offer avenues for future research. First, theoretically, we only took into consideration resonant leadership as a leadership style to study compassion at work. Future researchers could consider other forms of leadership to examine how leadership behaviours can help management policy makers to ensure compassion at work. Second, we consider the positive role of friendship at work in this study. However, from a critical perspective, friendship at work can also affect healthcare service performance by distracting the attention of nurses and other frontline staff while serving patients. Future studies could examine this interesting area of inquiry by considering the dark side of friendship when providing healthcare services. Third, methodologically, the data are cross-sectional in nature and are collected from frontline employees only, although we took some statistical measures to ensure that common method bias is not a problem in this study. However, we still recommend that future researchers consider collecting data at different time intervals and from multiple sources, i.e. employees and their supervisors. Finally, the context of this study is limited to healthcare settings, which is a strength in itself, though future researchers could collect data from other different sectors to improve the generalizability of the findings. Compassionate feelings are important among other service providers working in day care centres and charity organizations.

\section{References}

Allen, N. J., \& Meyer, J. P. (1990). The measurement and antecedents of affective, continuance and normative commitment to the organization. Journal of occupational psychology, 63(1), 1-18.

Ansari, A. R., \& Kashif, M. (2019). Few glitters are original gold. Asia Pacific Journal of Marketing and Logistics, 32(3), 747-767.

Bandura, A. (1977). Social learning theory. Englewood Cliffs, New Jersey: Prentice Hall.

Bandura, A. (1986). Social foundation of thought and action: A social-cognitive view. Englewood Universidad de Michigan, Michigan: Prentice Hall.

Bandura, A., \& Walters, R. H. (1977). Social learning theory. Michigan University: Prentice Hall.

Bawafaa, E., Wong, C. A., \& Laschinger, H. (2015). The influence of resonant leadership on the structural empowerment and job satisfaction of registered nurses. Journal of Research in Nursing, 20(7), 610-622.

Bernerth, J. B., Walker, H. J., \& Harris, S. G. (2016). Rethinking the benefits and pitfalls of leader-member exchange: A reciprocity versus self-protection perspective. Human relations, 69(3), 661-684. 
Borhani, F., Jalali, T., Abbaszadeh, A., \& Haghdoost, A. (2014). Nurses' perception of ethical climate and organizational commitment. Nursing ethics, 21(3), 278-288.

Boyatzis, R., \& McKee, A. (2013). Resonant Leadership: Renewing yourself and connecting with others through mindfulness, hope and compassion. Harvard University, Cambridge: Harvard Business Press.

Bryman, A. (2015). Social research methods (5th ed.). New York: Oxford university press.

Chan, S. C. H., \& Mak, W. M. (2014). Transformational leadership, pride in being a follower of the leader and organizational commitment. Leadership \& Organization Development Journal, 35(8), 674-690.

Chang, H.-T., Chou, Y.-J., Liou, J.-W., \& Tu, Y. -T. (2016). The effects of perfectionism on innovative behavior and job burnout: Team workplace friendship as a moderator. Personality and Individual Differences, 96, 260-265.

Chao, C. (2018, December). Does it work? Research on the relationship between workplace friendship and job performance- the organizational commitment as mediator. Proceedings of the International Conference on Education, E-learning and Management Technology (EEMT), Zhaoqing University, Guangdong, China, 3. Retrieved from https:// www.atlantis-press.com/proceedings/iceemt-18/55907719

Chen, Z., Zhu, J., \& Zhou, M. (2015). How does a servant leader fuel the service fire? A multilevel model of servant leadership, individual self identity, group competition climate, and customer service performance. Journal of Applied Psychology, 100(2), 511.

Chiaburu, D. S., \& Harrison, D. A. (2008). Do peers make the place? Conceptual synthesis and meta-analysis of coworker effects on perceptions, attitudes, OCBs, and performance. Journal of Applied Psychology, 93(5), 1082.

Coetzee, M., Ferreira, N., \& Potgieter, I. (2019). Perceptions of sacrifice, workplace friendship and career concerns as explanatory mechanisms of employees' organisational commitment. SA Journal of Human Resource Management, 17(1), 1-9.
Cummings, G. (2004). Investing relational energy: The hallmark of resonant leadership. Nursing Leadership (Toronto, Ont.), 17(4), 76-87.

Cummings, G. G., MacGregor, T., Davey, M., Lee, H., Wong, C. A., Lo, E., . . S Stafford, E. (2010). Leadership styles and outcome patterns for the nursing workforce and work environment: a systematic review. International journal of nursing studies, 47(3), 363-385.

Dutton, J. E., Roberts, L. M., \& Bednar, J. (2010). Pathways for positive identity construction at work: Four types of positive identity and the building of social resources. Academy of Management Review, 35(2), 265-293.

Dutton, J. E., Workman, K. M., \& Hardin, A. E. (2014). Compassion at work. Annual Review of Organizational Psychology and Organizational Behavior, 1(1), 277-304

Dutton, J. E., Worline, M. C., Frost, P. J., \& Lilius, J. (2006). Explaining compassion organizing. Administrative Science Quarterly, 51(1), 59-96.

Estabrooks, C. A., Squires, J. E., Cummings, G. G., Birdsell, J. M., \& Norton, P. G. (2009). Development and assessment of the Alberta Context Tool. BMC health services research, 9(1), 234.

Estabrooks, C. A., Squires, J. E., Hayduk, L. A., Cummings, G. G., \& Norton, P. G. (2011). Advancing the argument for validity of the Alberta Context Tool with healthcare aides in residential long-term care. BMC medical research methodology, 11(1), 107.

Frost, P. J., Dutton, J. E., Maitlis, S., Lilius, J. M., Kanov, J. M., \& Worline, M. C. (2006). Seeing organizations differently: Three lenses on compassion. The Sage handbook of organization studies, 2, 843-866.

Gatling, A., Kang, H. J. A., \& Kim, J. S. (2016). The effects of authentic leadership and organizational commitment on turnover intention. Leadership \& Organization Development Journal, 37(2), 181-199.

Ge, J., Wu, J., Li, K., \& Zheng, Y. (2019). Self-compassion and Subjective well-being mediates the impact of mindfulness on balanced time perspective in Chinese College Students. Frontiers in psychology, 10, 367. 
Glazer, S., \& Kruse, B. (2008). The role of organizational commitment in occupational stress models. International Journal of Stress Management, 15(4), 329.

Goleman, D., Boyatzis, R. E., \& McKee, A. (2013). Primal leadership: Unleashing the power of emotional intelligence. Boston, Massachusetts: Harvard Business Press.

Grant, A. M., Dutton, J. E., \& Rosso, B. D. (2008). Giving commitment: Employee support programs and the prosocial sensemaking process. Academy of Management Journal, 51(5), 898-918.

Hair, J. F. Jr., Hult, G. T. M., Ringle, C., \& Sarstedt, M. (2016). A primer on partial least squares structural equation modeling (PLS-SEM). Los Angeles: Sage Publications.

Hair, J. F., Ringle, C. M., \& Sarstedt, M. (2011). PLSSEM: Indeed a silver bullet. Journal of Marketing theory and Practice, 19(2), 139-152.

Hair, J. Jr., Sarstedt, M., Hopkins, L., \& G. Kuppelwieser, V. (2014). Partial least squares structural equation modeling (PLS-SEM): An emerging tool in business research. European Business Review, 26(2), 106-121

Herman, H., Dasborough, M. T., \& Ashkanasy, N. M. (2008). A multi-level analysis of team climate and interpersonal exchange relationships at work. The Leadership Quarterly, 19(2), 195-211.

Hur, W.-M., Moon, T.-W., \& Ko, S. -H. (2018). How employees' perceptions of CSR increase employee creativity: Mediating mechanisms of compassion at work and intrinsic motivation. Journal of Business Ethics, 153(3), 629-644.

Huyghebaert, T., Gillet, N., Audusseau, O., \& Fouquereau, E. (2019). Perceived career opportunities, commitment to the supervisor, social isolation: Their effects on nurses' well-being and turnover. Journal of nursing management, 27(1), 207-214.

Jang, J., \& Kandampully, J. (2018). Reducing employee turnover intention through servant leadership in the restaurant context: A mediation study of affective organizational commitment. International Journal of Hospitality \& Tourism Administration, 19(2), 125-141.

Kanov, J. M., Maitlis, S., Worline, M. C., Dutton, J. E., Frost, P. J., \& Lilius, J. M. (2004). Compassion in organizational life. American Behavioral Scientist, 47(6), 808-827.

Kashif, M., Zarkada, A., \& Thurasamy, R. (2017a). Customer aggression and organizational turnover among service employees: The moderating role of distributive justice and organizational pride. Personnel Review, 46(8), 1672-1688.

Kashif, M., Zarkada, A., \& Thurasamy, R. (2017b). The moderating effect of religiosity on ethical behavioural intentions: An application of the extended theory of planned behaviour to Pakistani bank employees. Personnel Review, 46(2), 429-448.

Koman, E. S., \& Wolff, S. B. (2008). Emotional intelligence competencies in the team and team leader: A multi-level examination of the impact of emotional intelligence on team performance. Journal of Management Development, 27(1), 55-75.

Krannitz, M. A., Grandey, A. A., Liu, S., \& Almeida, D. A. (2015). Workplace surface acting and marital partner discontent: Anxiety and exhaustion spillover mechanisms. Journal of occupational health psychology, 20(3), 314.

Kumasey, A. S., Bawole, J. N., \& Hossain, F. (2017). Organizational commitment of public service employees in Ghana: Do codes of ethics matter? International Review of Administrative Sciences, 83(Suppl), 59-77.

Laschinger, H. K. S., Wong, C. A., Cummings, G. G., \& Grau, A. L. (2014). Resonant leadership and workplace empowerment: The value of positive organizational cultures in reducing workplace incivility. Nursing Economics, 32(1), 5.

Lee, H. -J., \& Reade, C. (2018). The role of Yin-Yang leadership and cosmopolitan followership in fostering employee commitment in China: a paradox perspective. Cross Cultural \& Strategic Management, 25(2), 276-298.

Liden, R. C., Wayne, S. J., Liao, C., \& Meuser, J. D. (2014). Servant leadership and serving culture: Influence on individual and unit performance. Academy of Management Journal, 57(5), 1434-1452.

Lilius, J. M., Kanov, J., Dutton, J., Worline, M. C., \& Maitlis, S. (2011). Compassion revealed: What we know 
about compassion at work (and where we need to know more). Ann Arbor, 1001, 48109.

Lilius, J. M., Worline, M. C., Dutton, J. E., Kanov, J. M., \& Maitlis, S. (2011). Understanding compassion capability. Human relations, 64(7), 873-899.

Lilius, J. M., Worline, M. C., Maitlis, S., Kanov, J., Dutton, J. E., \& Frost, P. (2008). The contours and consequences of compassion at work. Journal of Organizational Behavior, 29(2), 193-218.

Lim, D. H., Kim, W., \& Shin, H. Y. (2019). Career adaptability and active job search behavior of Korean older workers. International Journal of Manpower, 40(7), 1239-1253.

Madden, L. T., Duchon, D., Madden, T. M., \& Plowman, D. A. (2012). Emergent organizational capacity for compassion. Academy of Management Review, 37(4), 689-708.

Marques, J. F. (2010). Awakened leaders: Born or made? Leadership \& Organization Development Journal, 31(4), 307-323.

Mawritz, M. B., Folger, R., \& Latham, G. P. (2014). Supervisors' exceedingly difficult goals and abusive supervision: The mediating effects of hindrance stress, anger, and anxiety. Journal of Organizational Behavior, 35(3), 358-372.

Mawritz, M. B., Mayer, D. M., Hoobler, J. M., Wayne, S. J., \& Marinova, S. V. (2012). A trickle-down model of abusive supervision. Personnel Psychology, 65(2), 325-357.

McCormick, L., \& Donohue, R. (2016). Antecedents of affective and normative commitment of organisational volunteers. The International Journal of Human Resource Management, 2581-2604

McCormick, L., \& Donohue, R. (2019). Antecedents of affective and normative commitment of organisational volunteers. The International Journal of Human Resource Management, 30(18), 2581-2604.

Melwani, S., Mueller, J. S., \& Overbeck, J. R. (2012). Looking down: The influence of contempt and compassion on emergent leadership categorizations. Journal of Applied Psychology, 97(6), 1171.
Methot, J. R., Lepine, J. A., Podsakoff, N. P., \& Christian, J. S. (2016). Are workplace friendships a mixed blessing? Exploring tradeoffs of multiplex relationships and their associations with job performance. Personnel Psychology, 69(2), 311-355.

Meyer, J. P., \& Allen, N. J. (1997). Commitment in the workplace: Theory, research, and application. Thousand Oaks, California: Sage publications, Inc.

Meyer, J. P., Allen, N. J., \& Smith, C. A. (1993). Commitment to organizations and occupations: Extension and test of a three-component conceptualization. Journal of applied psychology, 78(4), 538.

Min, H., Park, J., \& Kim, H. J. (2016). Common method bias in hospitality research: A critical review of literature and an empirical study. International Journal of Hospitality Management, 56, 126-135.

Morrison, R. L. (2009). Are women tending and befriending in the workplace? Gender differences in the relationship between workplace friendships and organizational outcomes. Sex Roles, 60(1-2), 1.

Mowday, R. T., Steers, R. M., \& Porter, L. W. (1978). The measurement of organizational commitment. Journal of vocational behavior, 14(2), 224-247.

Neuman, W., \& Robson, K. (2012). Basics of social research: Qualitative and quantitative approaches (2nd ed.). Canada: Pearson.

Nguyen, D. T., Teo, S. T., Pick, D., \& Jemai, M. (2018). Cynicism about change, work engagement, and job satisfaction of public sector nurses. Australian Journal of Public Administration, 77(2), 172-186.

Nielsen, I. K., Jex, S. M., \& Adams, G. A. (2000). Development and validation of scores on a two-dimensional workplace friendship scale. Educational and Psychological Measurement, 60(4), 628-643.

Nowak, R. (2019). Developing serving culture: Focus on workplace empowerment. Employee Relations: The International Journal, 41(6), 1312-1329.

Podsakoff, P. M., MacKenzie, S. B., \& Podsakoff, N. P. (2012). Sources of method bias in social science research 
and recommendations on how to control it. Annual review of psychology, 63, 539-569.

Podsakoff, P. M., MacKenzie, S. B., Lee, J.-Y., \& Podsakoff, N. P. (2003). Common method biases in behavioral research: A critical review of the literature and recommended remedies. Journal of applied psychology, 88(5), 879.

Rai, A., \& Agarwal, U. A. (2018a). Examining workplace bullying-outcomes relationships among Indian managers: Psychological contract violation as mediator and workplace friendship as moderator. Employee Relations, 40(6), 1015-1035.

Rai, A., \& Agarwal, U. A. (2018b). Workplace bullying and employee silence: A moderated mediation model of psychological contract violation and workplace friendship. Personnel Review, 47(1), 226-256.

Randall, D. M., \& Gibson, A. M. (2013). Methodology in business ethics research: A review and critical assessment. Citation Classics from the Journal of Business Ethics, 191-211.

Reader, T. W., Mearns, K., Lopes, C., \& Kuha, J. (2017). Organizational support for the workforce and employee safety citizenship behaviors: A social exchange relationship. Human relations, 70(3), 362-385.

Rhee, S.-Y., Hur, W.-M., \& Kim, M. (2017). The relationship of coworker incivility to job performance and the moderating role of self-efficacy and compassion at work: The Job Demands-Resources (JD-R) approach. Journal of Business and Psychology, 32(6), 711-726.

Saunders, M. N. (2011). Research methods for business students (5th ed.). Harlow, England: Pearson Education India.

Schriesheim, C. A. (1979). The similarity of individual directed and group directed leader behavior descriptions. Academy of Management Journal, 22(2), 345-355.

Schwepker, C. H., Jr., Dimitriou, C. K., \& McClure, T. (2019). Reducing service sabotage and improving employee commitment to service quality. Journal of Services Marketing, 33(5), 615-625

Shahzad, K., \& Muller, A. R. (2016). An integrative conceptualization of organizational compassion and organizational justice: A sensemaking perspective. Business Ethics: A European Review, 25(2), 144-158.

Sharma, P., Kong, T. T. C., \& Kingshott, R. P. (2016). Internal service quality as a driver of employee satisfaction, commitment and performance: Exploring the focal role of employee well-being. Journal of Service Management, 27(5), 773-797.

Sias, P. M. (2005). Workplace relationship quality and employee information experiences. Communication studies, 56(4), 375-395.

Simpson, A. V., Clegg, S., \& Pina e Cunha, M. (2013). Expressing compassion in the face of crisis: Organizational practices in the aftermath of the Brisbane floods of 2011. Journal of Contingencies and Crisis Management, 21(2), $115-124$.

Singh, A., Sengupta, S., \& Sharma, S. (2018). Empathy and mindfulness: Exploring the possible predictors of authentic leadership. In V. Ahuja \& S. Rathore (Ed.). Multidisciplinary perspectives on human capital and Information Technology Professionals (Cap. 15, pp. 290307). Hersey PA, USA: IGI Global.

Song, S.-H., \& Olshfski, D. (2008). Friends at work: A comparative study of work attitudes in Seoul city government and New Jersey state government. Administration \& Society, 40(2), 147-169.

Spandler, H., \& Stickley, T. (2011). No hope without compassion: the importance of compassion in recoveryfocused mental health services. Journal of Mental Health, $20(6), 555-566$

Spanuth, T., \& Wald, A. (2017). Understanding the antecedents of organizational commitment in the context of temporary organizations: An empirical study. Scandinavian Journal of Management, 33(3), 129-138.

Tekingündüz, S., Top, M., Tengilimoğlu, D., \& Karabulut, E. (2017). Effect of organisational trust, job satisfaction, individual variables on the organisational commitment in healthcare services. Total Quality Management \& Business Excellence, 28(5-6), 522-541.

van Gelderen, B. R., Konijn, E. A., \& Bakker, A. B. (2017). Emotional labor among police officers: A diary 
study relating strain, emotional labor, and service performance. The International Journal of Human Resource Management, 28(6), 852-879.

Wagner, J., Warren, S., Cummings, G., L. Smith, D., \& K. Olson, J. (2014). Workplace model for physical therapists and occupational therapists. Journal of health organization and management, 28(3), 290-314.

Wagner, J., Warren, S., Cummings, G., Smith, D. L., \& Olson, J. K. (2013). Resonant leadership, workplace empowerment, and "Spirit at Work": Impact on RN job satisfaction and organizational commitment. Canadian Journal of Nursing Research, 45(4), 108-128.
Younas, A., \& Maddigan, J. (2019). Proposing a policy framework for nursing education for fostering compassion in nursing students: A critical review. Journal of advanced nursing, 75, 1621-1636.

Zoghbi-Manrique-de-Lara, P., \& Viera-Armas, M. (2019). Does ethical leadership motivate followers to participate in delivering compassion? Journal of Business Ethics, 154, 195-210.

Zulueta, P. C. (2016). Developing compassionate leadership in health care: An integrative review. Journal of Healthcare Leadership, 8, 1. 
Appendix A - Research Questionnaire

\begin{tabular}{|c|c|c|c|c|c|c|}
\hline \multicolumn{2}{|c|}{ Gender } & \multicolumn{2}{|c|}{ Age } & \multicolumn{2}{|c|}{ Job tenure } & \multirow[t]{2}{*}{$\begin{array}{l}\text { What sector/industry do you } \\
\text { work in? }\end{array}$} \\
\hline o & Male & o & 21 to 30 & o & Less than 1 year & \\
\hline & & o & 31 to 40 & o & 1 to 5 years & What is your job title/role? \\
\hline \multirow[t]{2}{*}{ o } & Female & o & 41 to 50 & o & 6 to 10 years & \\
\hline & & o & More than 50 & o & $\begin{array}{c}\text { More than } \\
10 \text { years }\end{array}$ & \\
\hline
\end{tabular}

Please indicate the extent to which you agree or disagree with each statement.

Leadership Behaviour:

\begin{tabular}{|c|c|c|c|c|c|c|}
\hline RL & My Supervisor... & $\begin{array}{l}\text { Strongly } \\
\text { Disagree }\end{array}$ & Disagree & Neutral & Agree & $\begin{array}{c}\text { Strongly } \\
\text { Agree }\end{array}$ \\
\hline 1 & seeks feedback even when it is difficult to hear. & 1 & 2 & 3 & 4 & 5 \\
\hline 2 & acts on their values even if it is at a personal cost. & 1 & 2 & 3 & 4 & 5 \\
\hline 3 & focuses on successes rather than failures. & 1 & 2 & 3 & 4 & 5 \\
\hline 4 & supports teamwork to achieve goals/outcomes. & 1 & 2 & 3 & 4 & 5 \\
\hline 5 & calmly handles stressful situations. & 1 & 2 & 3 & 4 & 5 \\
\hline 6 & $\begin{array}{l}\text { actively listens, acknowledges, and then responds } \\
\text { to requests and concerns. }\end{array}$ & 1 & 2 & 3 & 4 & 5 \\
\hline 7 & $\begin{array}{l}\text { actively mentors or coaches the performance of } \\
\text { others. }\end{array}$ & 1 & 2 & 3 & 4 & 5 \\
\hline 8 & effectively resolves conflicts that arise. & 1 & 2 & 3 & 4 & 5 \\
\hline 9 & engages me in working towards a shared vision. & 1 & 2 & 3 & 4 & 5 \\
\hline 10 & $\begin{array}{l}\text { allows me the freedom to make important } \\
\text { decisions in my work. }\end{array}$ & 1 & 2 & 3 & 4 & 5 \\
\hline
\end{tabular}

Serving Culture:

\begin{tabular}{|c|c|c|c|c|c|c|}
\hline SC & Managers and employees at my workplace...... & $\begin{array}{l}\text { Strongly } \\
\text { Disagree }\end{array}$ & Disagree & Neutral & Agree & $\begin{array}{c}\text { Strongly } \\
\text { Agree }\end{array}$ \\
\hline 11 & $\begin{array}{l}\text { can say when something related to work is going } \\
\text { wrong. }\end{array}$ & 1 & 2 & 3 & 4 & 5 \\
\hline 12 & make employee career development a priority. & 1 & 2 & 3 & 4 & 5 \\
\hline 13 & $\begin{array}{l}\text { would seek help from others if they had a } \\
\text { personal problem. }\end{array}$ & 1 & 2 & 3 & 4 & 5 \\
\hline 14 & $\begin{array}{l}\text { emphasize the importance of giving back to the } \\
\text { community. }\end{array}$ & 1 & 2 & 3 & 4 & 5 \\
\hline 15 & put others' best interests ahead of their own. & 1 & 2 & 3 & 4 & 5 \\
\hline 16 & $\begin{array}{l}\text { give others the freedom to handle difficult } \\
\text { situations in the way that they feel is best. }\end{array}$ & 1 & 2 & 3 & 4 & 5 \\
\hline 17 & $\begin{array}{l}\text { would NOT compromise on ethical principles in } \\
\text { order to achieve success. }\end{array}$ & 1 & 2 & 3 & 4 & 5 \\
\hline
\end{tabular}

Workplace Friendship:

\begin{tabular}{llcccc}
\hline WF & \multicolumn{1}{c}{ In my organization...... } & $\begin{array}{c}\text { Strongly } \\
\text { Disagree }\end{array}$ & Disagree & Neutral & $\begin{array}{c}\text { Strongly } \\
\text { Agree }\end{array}$ \\
\hline $\mathbf{1 8}$ & I have formed strong friendships at work. & 1 & 2 & 3 & 4 \\
$\mathbf{1 9}$ & I socialize with coworkers outside the workplace. & 1 & 2 & 3 & 4 \\
$\mathbf{2 0}$ & I can confide in people at work. & 1 & 2 & 3 & 4 \\
$\mathbf{2 1}$ & I feel I can trust many coworkers a great deal. & & 3 & 5 \\
$\mathbf{2 2}$ & $\begin{array}{l}\text { being able to see my coworkers is the reason I } \\
\text { look forward to my job. }\end{array}$ & 1 & 2 & 3 & 5 \\
$\mathbf{2 3}$ & I feel that someone I work with is a true friend. & 1 & 2 & 3 & 5 \\
\hline
\end{tabular}


Compassion at Work:

\begin{tabular}{|c|c|c|c|c|c|c|}
\hline CAW & When you are in painful circumstances...... & Never & Rarely & Sometimes & Often & $\begin{array}{c}\text { Nearly all } \\
\text { the time }\end{array}$ \\
\hline 24 & how often do you experience compassion on the job? & 1 & 2 & 3 & 4 & 5 \\
\hline 25 & $\begin{array}{l}\text { how often do you experience compassion from your } \\
\text { supervisor? }\end{array}$ & 1 & 2 & 3 & 4 & 5 \\
\hline 26 & $\begin{array}{l}\text { how often do you experience compassion from your } \\
\text { coworkers? }\end{array}$ & 1 & 2 & 3 & 4 & 5 \\
\hline
\end{tabular}

Normative Commitment:

\begin{tabular}{|c|c|c|c|c|c|c|}
\hline NC & Normative Commitment & $\begin{array}{l}\text { Strongly } \\
\text { Disagree }\end{array}$ & Disagree & Neutral & Agree & $\begin{array}{c}\text { Strongly } \\
\text { Agree }\end{array}$ \\
\hline 27 & $\begin{array}{l}\text { I feel an obligation to remain with my current } \\
\text { employer. }\end{array}$ & 1 & 2 & 3 & 4 & 5 \\
\hline 28 & $\begin{array}{l}\text { Even if it were to my advantage, I do not feel it would } \\
\text { be right to leave my organization now. }\end{array}$ & 1 & 2 & 3 & 4 & 5 \\
\hline 29 & I would feel guilty if I left my organization now. & 1 & 2 & 3 & 4 & 5 \\
\hline 30 & This organization deserves my loyalty. & 1 & 2 & 3 & 4 & 5 \\
\hline 31 & $\begin{array}{l}\text { I would not leave my organization right now because } \\
\text { I have a sense of obligation to the people in it. }\end{array}$ & 1 & 2 & 3 & 4 & 5 \\
\hline 32 & I owe a great deal to my organization. & 1 & 2 & 3 & 4 & 5 \\
\hline
\end{tabular}




\section{Authors:}

1. Riaz Ali, Master, GIFT University, Gujranwla, Pakistan.

E-mail: riazali0347@gmail.com

ORCID

(iD) 0000-0002-715-1210

2. Muhammad Kashif, Master, GIFT University, Gujranwala, Pakistan.

E-mail: kashif@gift.edu.pk

ORCID

(D) $0000-0003-1274-6742$

\section{Contribution of each author}

\begin{tabular}{lcc}
\hline \multicolumn{1}{c}{ Contribution } & Riaz Ali & Muhammad Kashif \\
\hline 1. Definition of research problem & $\sqrt{ }$ & $\sqrt{ }$ \\
2. Development of hypotheses or research questions (empirical studies) & $\sqrt{ }$ \\
3. Development of theoretical propositions (theoretical work) & $\sqrt{ }$ & $\sqrt{ }$ \\
4. Theoretical foundation/literature review & $\sqrt{ }$ \\
5. Definition of methodological procedures & $\sqrt{ }$ \\
6. Data collection & $\sqrt{ }$ & $\sqrt{ }$ \\
7. Statistical analysis & $\sqrt{ }$ \\
8. Analysis and interpretation of data & & $\sqrt{ }$ \\
9. Critical revision of the manuscript & & $\sqrt{ }$ \\
10. Manuscript writing & & $\sqrt{ }$ \\
11. Other (journal correspondence and improvements as per reviewer comments) & \\
\hline
\end{tabular}

